\title{
DESIGN AND FABRICATION OF A MULTIPURPOSE RAILROAD HAND TRUCK
}

\author{
C. N. Nwogu ${ }^{1, *}$, B. N. Nwankwojike ${ }^{2}$, C. Anyaregbu ${ }^{3}$ and C. Arisa ${ }^{4}$

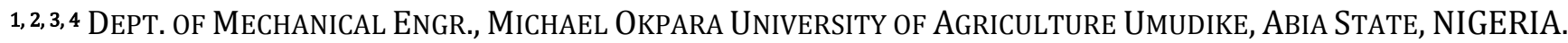 \\ E-mail addresses: ${ }^{1}$ checknolly@yahoo.com, ${ }^{2}$ jikeobodo@gmail.com, ${ }^{3}$ patickchrisanthus@yahoo.com, \\ 4 arimark2020@gmail.com
}

\begin{abstract}
A multipurpose railroad hand truck comprising mainly of a frame, swinger arm, connecting rod, crank shaft, gears, wheels and brake was designed and fabricated to reduce the cost of material handling in small scaled manufacturing industries. The frame and other major components of the hand truck were fabricated with mild steel bars, shafts and sheets while the guide rail was constructed using $50 \mathrm{~mm}$ by $50 \mathrm{~mm}$ mild steel angle bar. The hand truck is hand paddled and requires no prime mover (electric motor, IC engine, etc.), hence incurring minimal operational cost. The hand truck will be used to convey tools, materials and work pieces from one part of the workshop to another on guide rails. Results of its performance test indicated that the hand truck can carry loads up to $250 \mathrm{~kg}$. All materials used for the fabrication were sourced locally.
\end{abstract}

Keywords: railroad, truck, paddled, swinger, multipurpose

\section{INTRODUCTION}

Material handling is one of many factors that contribute to the improvement of a company's performance. The Materials Handling Industry of America [MHIA] defines materials handling as the movement, storage, control and protection of materials, goods, and products throughout the process of manufacturing, distribution, consumption and disposal $[1,2]$. The primary objective of a material handling system is to reduce the unit cost of production. It utilizes a wide range of manual, semi-automated, and automated equipment and includes consideration of the protection, storage, and control of materials throughout their manufacturing, warehousing, distribution, consumption, and disposal. By means of effective material handling management, a company's operational performance may improve, aiming to satisfy the customers or meet their expectations in terms of their needs, desires and demands [3-5]. Industries, workshops, and other places of activities require the movement of tools, workpieces and other materials from one point to another. Hence, the need for a durable and efficient material handling system and equipment. Various hand trucks have been developed for this purpose.

Hand truck also known as floor truck, two wheeler, stack truck, trolley, trundle, box cart, trolley truck[6]is a machine that permits mechanized pick up and deposit of loads, eliminating partially the lifting of loads and transportation. Hand trucks are grouped into two divisions, two wheel hand trucks and multiple wheel hand trucks. Multiple wheel hand trucks are those having more than two wheels and are used mostly for horizontal movements. These units are often used in tow line (tow conveyor) operations, where they are pulled by a power unit driving an overhead or under floor chain or trailertrain operations.

Hand trucks can also be classified according to use. Many of the truck are of general application in manufacturing plants, warehouses, terminals, departmental stores, delivery services, and numerous other industries. Other types of trucks are of specialized nature for handling particular type of materials and commodities where certain requirements exist.

A good placement of facilities contributes to the overall efficiency of operations and can reduce up to $50 \%$ the total operating expenses [7] Industries, factories, plants, workshops, etc face challenges in the design of efficient layout system. Most industries or workshops make use of the fixed position layouts because of its numerous advantages but the major deficiency, is the increased movement of personnel, equipment, materials, and tools which also increases the cost of handling these physical matters. In a fixed position layout, personnel, supplies, and equipment are brought to the site where the product will be assembled, rather than the product being moved through an assembly line. One of the major setback of this layout is the difficulty in moving materials, personnel and tools to various sections of the job and 
this is the aim of this research. Existing hand trucks have been plagued with issues like; low mechanical advantage, disorderliness and littering of the workshop space after use. The operator expends relatively high energy to move heavy objects. This causes fatigue and in some cases may pose a health risk especially where the hand truck has to be used repeatedly on daily basis. Also, disorderliness in a workshop may cause obstruction of movement in case of emergency. To eliminate these problems, a hand paddled rail-road hand truck is designed for movement of goods and materials in workshops.

The main objective of this work is the design and fabrication of a multipurpose rail road hand truck for easy movement of tools and materials in workshops, factories, warehouses and other places that require movement of materials within the confines of a building. Specific objectives include:

i. Development of a modified position layout (with rail conveying system) to enhance easy and safe movement of objects in factories and workshops as well as optimize available floor space.

ii. Performance evaluation of the multipurpose railroad truck.

\section{MATERIALS AND METHODS}

The materials used in the fabrication of the multipurpose rail road hand truck are as follows: Mild steel Pulleys, mild steel angle bar ( $5 \mathrm{~mm}$ thickness), $3 \mathrm{~mm}$ mild steel plate, mild steel pipe (6mm diameter), mild steel rod (8 mm diameter), Spur gears, Paint, Helical Spring, Bolt and Nut: M16x2.0

\subsection{Design Methodology and Analysis}

\subsubsection{Design Concept and Considerations}

The design, material selection and development of the multipurpose rail road hand truck were based on the following concepts and considerations:

i. Movement of the hand truck is confined within a rail system to prevent unnecessary littering of the workshop and enhance safe movement of people.

ii. The hand truck was developed using locally sourced standard materials to ensure low cost of production and maintenance.

iii. The hand truck requires no external power source for its movement. Hence, minimal operational cost is incurred.

iv. The hand truck was designed rigidly to efficiently carry tools and work piece around the workshop without failing / buckling.

\subsubsection{Mechanical Advantage and Velocity Ratio of the Hand Truck}

The force exerted on the swinger arm by the operator of the hand truck must be less than the weight of the load required to be moved. Hence, mechanical advantage must be greater than one. The mechanical advantage can be determined by considering the balance of moments or torque, $\mathrm{T}$, about the fulcrum. This is the ratio of output force to input force and is calculated using:

$$
M A=\frac{\text { load on the hand truck }}{\text { downward force on the swinger arm }}
$$

Another measure towards achieving maximum performance of the hand truck is to ensure a velocity ratio (VR) greater than one. Two gears of $\phi 54 \mathrm{~mm}$ and $\phi 16 \mathrm{~mm}$ were therefore used as the driving and pinion gears respectively. The velocity ratio of the drive is determined using equation 2 [8 - 10].

$$
V R=\frac{D_{1}}{D_{2}}=\frac{N_{2}}{N_{1}}
$$

In (2), $D_{1}$ and $D_{2}$ are the diameters of the driving and driven gears respectively. $N_{1}$ and $N_{2}$ are the speeds of the driving and driven gears respectively.

\subsubsection{Determination of Initial Thrust Needed to Drive the Hand Truck}

Thrust is a reaction force described quantitatively by newton's second and third laws. When a system expels or accelerates mass in one direction, the accelerated mass will cause a force of equal magnitude but opposite direction on that system. Since the hand truck is not driven by a prime mover (electric motor, IC engine, etc.), an initial thrust is required to accelerate the hand truck from rest while paddling of the swinger arm keeps it in motion until the break is applied. The value of the thrust required to drive the handle under any load condition can be determined using equations 3-5.

$$
\begin{aligned}
& \quad f=\mu R \\
& R=m g \\
& m=w_{t}+w_{d}+f_{1}+P+r
\end{aligned}
$$

In (3) to (5), $f$ is the thrust, $\mu$ is the coefficient of friction ( 0.15 for clean and dry surfaces), $w$ is the weight of empty truck, $w_{d}$ is the weight of driver, $f_{1}$ is the downward force at swinger arm, $P$ is the load on the hand truck, $g$ is the acceleration due to gravity $\approx 9.8 \mathrm{~m} /$ $s^{2}$ and $r$ is the rolling resistance

Rolling resistance is a measure of the retarding effect of a floor surface at the tread/floor interface of the wheels [11]. It is normally expressed in pounds and is a measure of the energy dissipated per unit of distance rolled. Rolling resistance measures the energy lost as something is rolling a specific distance. The most significant factors that determine rolling resistance includes: load, wheel diameter, tread material/hardness, floor material/finish and floor conditions (roughness, cleanliness, slope, etc.). Rolling resistance is calculated using the relation: 


$$
r=f_{r} \frac{l}{R}
$$

Here, $f_{r}$ is the coefficient of rolling friction, $l$ is the load on the wheel and $R$ is the Radius of the wheel. Coefficient of rolling friction for different tread materials on steel floor is summarized in Table 1 below.

Table 1: Coefficient of rolling friction for different materials on steel floor

\begin{tabular}{cc}
\hline Tread material & Coefficient of rolling friction \\
\hline Forged steel & 0.019 \\
Cast iron & 0.021 \\
Hard rubber & 0.303 \\
Polyurethane & $0.030-0.057$ \\
Cast nylon & 0.027 \\
Phenolic & 0.026 \\
\hline
\end{tabular}

Source [11]

\subsubsection{Construction Procedure of the Rail Road Hand Truck}

The developed hand truck comprises of the following major parts: frame, swinger arm, connecting rod, crank shaft, gears, wheels, brake, bearings and guide rails. Figure 1 below shoes the isometric view of the hand truck on a guide rail section.

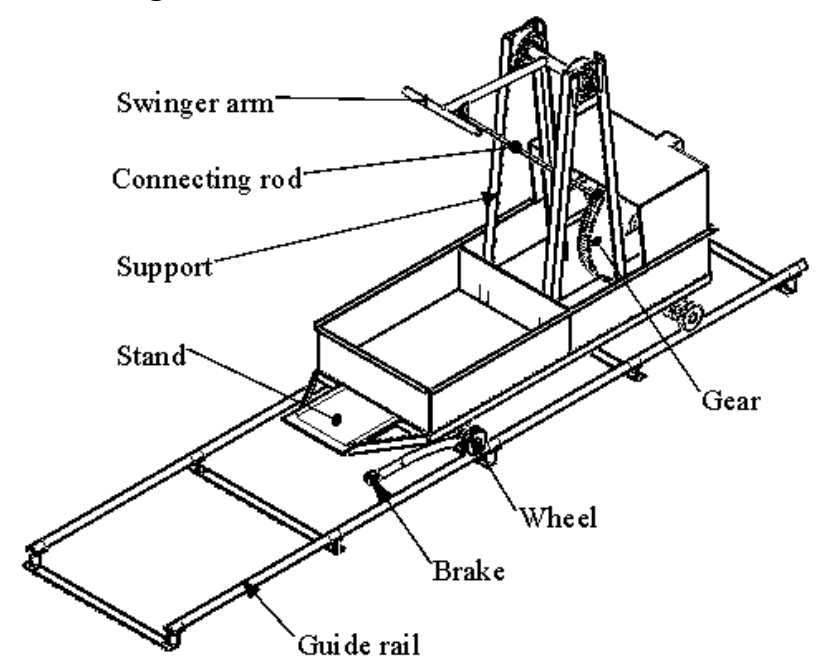

Figure 1: Isometric view of the hand truck on a guide rail section

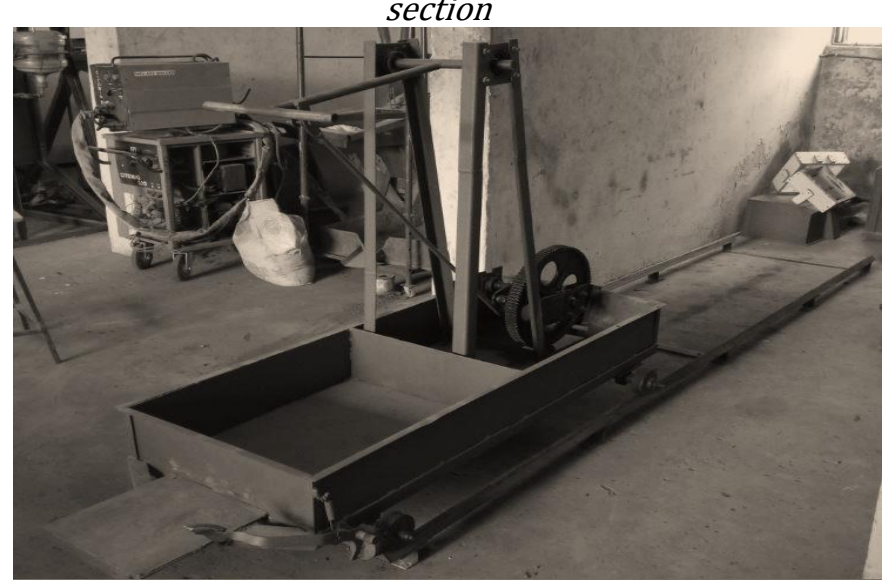

Figure 2: The rail road hand truck after construction
The frame is an assembly of welded sections upon which components such as the gear drive, bearings, stand, swinger arm, etc. are mounted. The frame ensures stability of the hand truck under load and was constructed using $50 \times 50 \times 5 \mathrm{~mm}$ mild steel angle bar. As part of the frame, two supports of height $1500 \mathrm{~mm}$ are located in the front half of the truck and a swinger arm is mounted on the supports by means of two ball bearings.

The swinger arm was fabricated using $500 \mathrm{~mm}$ length mild steel pipe of outer diameter $20 \mathrm{~mm}$. A similar pipe of $120 \mathrm{~mm}$ was welded to it, forming a T- shape at the free end to enable paddling with both hands. A connecting rod connected to the swinger arm transmits the force from the operator to a crankshaft. This crankshaft converts the reciprocating motion of the swinger arm into a rotary motion. This rotary motion is transmitted to the wheels by a pair of gears. The driving gear is a mild steel gear of $\$ 540 \mathrm{~mm}$ while the driven gear is a similar gear of $\phi 160 \mathrm{~mm}$. The hand truck moves on a guide rail made from two lengths of $50 \mathrm{~mm} \times 50 \mathrm{~mm}$ angle bars with equidistant supporting cross bars that hold the rail firmly and rigidly. Stoppage of the hand truck is achieved using a breaking system of class one. The break is located on the right side of the operator stand for easy and quick reach. The break consists of a spring return lever with a pedal at one end and rubber at the other end. Figure 2 shows a picture of the developed hand truck.

When the pedal is depressed in an attempt to stop the truck, the rubber at the other end makes contact with the right rear wheel and brings the hand truck to a halt. The spring mechanism allows the lever to return to its initial position once the pedal is released. The front, end and plan views of the hand truck are shown in $3^{\text {rd }}$ angle orthographic projection in Figure 3.

\subsection{Performance Test Procedure of the Hand Truck}

The time taken by the hand truck to carry various loads through specified distance (delivery time) as well as maximum load that can be moved on the hand truck were determined. To determine the maximum moveable load on the hand truck, bags of cement (Dangote Cement) were loaded intermittently and the hand truck driven until the hand truck was unable to be moved when loaded. The relationship between the delivery time of the hand truck and load was determined by moving different loads (flywheels) on the hand truck through a rail section of $10 \mathrm{~m}$ and recording the time taken by the hand truck to get to the end of the rail section. Flywheels were used in place of cement bags this time so that smaller weight increase $(10 \mathrm{~kg})$ can be obtained. 


\section{RESULTS AND DISCUSSION}

The results of the experimental investigation of the developed hand truck as per each experimental procedure described in section 2.2are presented and discussed in this section.

\subsection{Determination of Maximum Moveable Load}

Results of the experiment for the determination of the maximum moveable load on the hand truck is shown in Table 2.

Table 2:Maximum moveable load experiment.

\begin{tabular}{lllllll}
\hline Trial & $1^{\text {st }}$ & $2^{\text {nd }}$ & $3^{\text {rd }}$ & $4^{\text {th }}$ & $5^{\text {th }}$ & $6^{\text {th }}$ \\
\hline Weight (kg) & 50 & 100 & 150 & 200 & 250 & 300 \\
Distance moved & 10 & 10 & 10 & 10 & 10 & - \\
(m) & & & & & & \\
\hline
\end{tabular}

From Table 2, it can be seen that with loads of $50 \mathrm{~kg}$, $100 \mathrm{~kg}, 150 \mathrm{~kg}, 200 \mathrm{~kg}$ and $250 \mathrm{~kg}$ the truck successfully driven through a distance of $10 \mathrm{~m}$, but when loaded with $300 \mathrm{~kg}$, the truck was unable to be moved on the guide rail. This is because the force generated by the operator at this point was not enough to overcome the static friction of the hand truck (equation 3). $250 \mathrm{~kg}$ was therefore selected as the maximum moveable weight on the hand truck. It is important to note that heavier loads can be moved by stronger operators. Hence, the actual maximum moveable load on the hand truck varies from operator to operator. $250 \mathrm{~kg}$ was therefore chosen for convenience since it is the weight that any average man can move on the hand truck.

\subsection{Effect of Load Variation on Delivery Time}

Results of the experiment for the effect of load variation on delivery time is summarized in Table 3 below.

The weights were varied from $100 \mathrm{~kg}$ to $250 \mathrm{~kg}$, since $250 \mathrm{~kg}$ was determined as the maximum movable load. From Table 3, it can be seen that as the weight increases, the hand truck takes longer time to cover a specified distance. This is because heavier loads require more energy to move, thereby reducing the speed with which the operator paddles the swinger.

\section{CONCLUSION}

The multipurpose railroad hand truck designed and fabrication is capable of carrying loads up to $250 \mathrm{~kg}$. The hand truck requires no external power source for its operation hence, incurs no operational costs. Movement of the hand truck is confined to guide rails to optimize available workshop space.

This innovation is particularly useful to small and medium scaled industries due to its low cost and local material ingenuity.
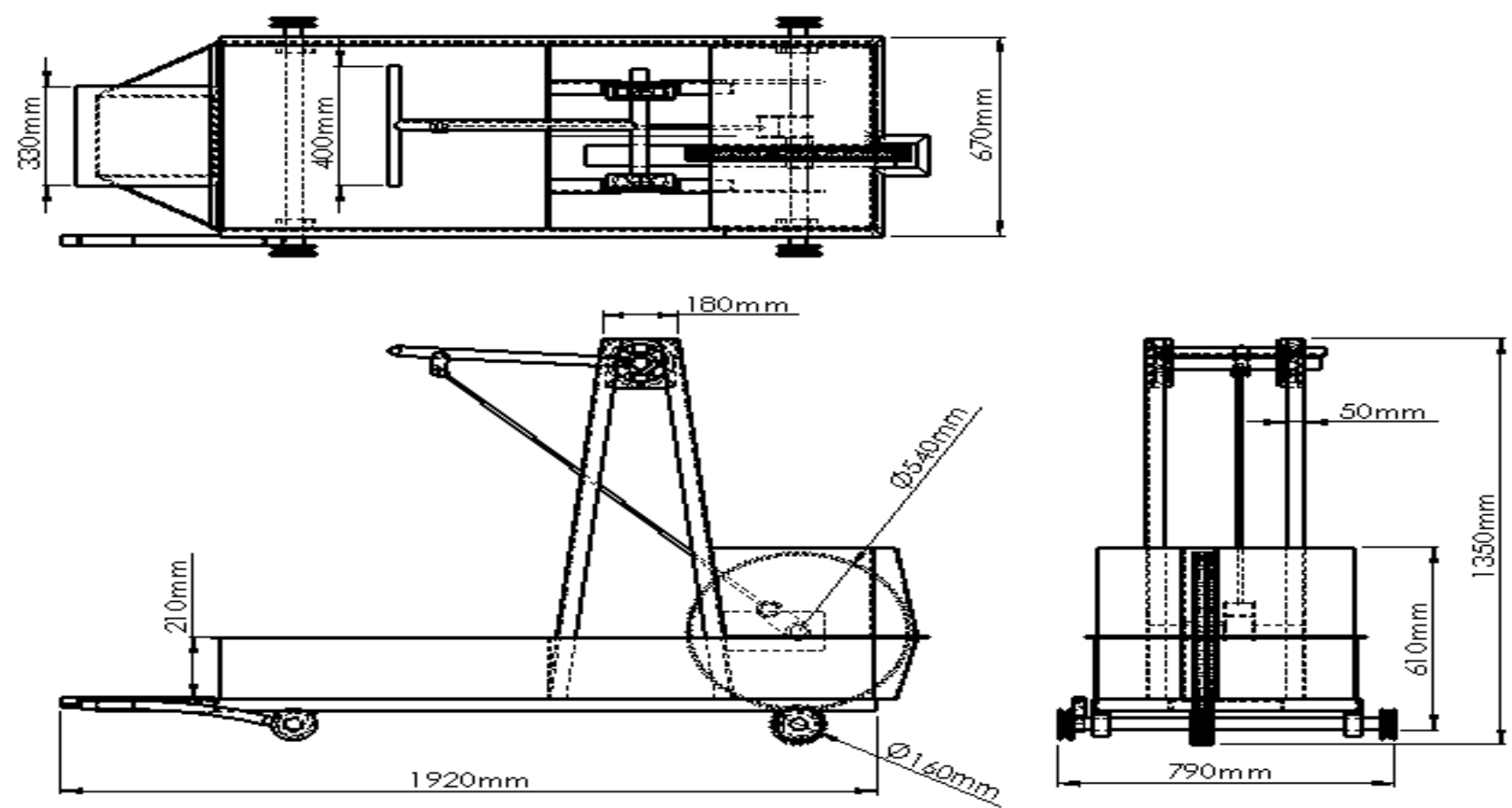

Figure 3: $3^{\text {rd }}$ angle orthographic projection of the hand truck

\begin{tabular}{|l|l} 
Weight $(\mathrm{kg})$ & 100 \\
& 180 \\
Time (sec) & 4.00 \\
& 4.66
\end{tabular}

Table 3: Effect of load variation on delivery time

$\begin{array}{lllllll}110 & 120 & 130 & 140 & 150 & 160 & 170 \\ 190 & 200 & 210 & 220 & 230 & 240 & 250 \\ 4.12 & 4.30 & 4.4 & 4.46 & 4.50 & 4.53 & 4.60 \\ 4.90 & 5.70 & 5.91 & 6.00 & 6.61 & 7.00 & 8.00\end{array}$




\section{RECOMMENDATIONS}

This study recommends further research to determine better ways of driving/moving the hand truck to reduce the energy required to drive the hand truck as well as increase the maximum moveable load. Also, further improvement in the design of the hand truck to enable left and right turns while moving on the guide rails is recommended.

\section{REFERENCES}

[1] Vieira G., Giovana S., Maria B., Gabriel S. and Alberto P. "Materials Handling Management: A Case Study". Journal of operations and supply chain management 4(2), Pp 19-30. 2011..

[2] Raymond A. Kulwiec. Materials Handling Handbook - American Society of Mechanical Engineers (ASME), International Material Management Society (IMMS). ISBN 9780470172490 - Google Books, 2008.

[3] Chopra S and Meindl. Supply Chain Management: Strategy, Planning and Operations. The University of California, Prentice hall, 2001.

[4] Rosenbloom S. The Mobility Needs of Older American: Implications for Transportation Reauthorization. The Brookings Institution; Center on Urban and Metropolitan Policy. Washington D C: 20036-2188, 2003.
[5] Eyob Ephrem and Edem Tetteh. "CustomerOriented Global Supply Chain: Concepts for Effective Management". Information Science Reference, , ISBN: 978-1-4666-0246-5. 2012.

[6] Kay Michael. Material Handling Equipment. Fitts Department of Industrial and Systems Engineering North Carolina State University, 2012.

[7] Sujono, S.; Lashkari, R. S. "A multi-objective model of operation allocation and material handling system selection in FMS design". International Journal of Production Economics, n. 105, p. 116133. 2007.

[8] Burr, A and Cheatham, J. Mechanical Desin and Analysis, 2nd edition ,section 5.2. Prentice- Hall, 1955.

[9] Khurmi R. S. and Gupta J. K. A Textbook of Machine Design (S. I. Units). Eurasis Publishing House (PVT) Limited, New Delhi-110 055, 2005.

[10] Sharma P. C. and Aggarwal D. K. Machine Design. S. K. Kataria and Sons, Nai Sarak Dechi. Katariabooks@yahoo.com, 2006.

[11] Lippert Dave and Jeff Spektor. "Calculating proper rolling resistance: a safer move to material handling". Plant engineering: www.plantengineering.com/index.php.Accessed on May 10, 2012. 